\section{Severe Cervical Kyphosis in Adolescent after Minor Trauma - A Case Report}

\author{
Kazuyuki Watanabe*, Shoji Yabuki, Koji Otani, Akira Onda, \\ Takuya Nikaido and Shin-ichi Konno
}

Department of Orthopaedic Surgery, Fukushima Medical University School of Medicine, Hikarigaoka, Fukushima, Japan

\begin{abstract}
Introduction: Cervical kyphotic deformity and myelopathy is very rare in adolescent. We experienced a case of the 16-year-old male who presented with cervical kyphosis following minor trauma of the neck.

Case presentation: A sixteen-year-old Japanese male had experienced mild neck pain after falling in the bathroom 3 months previously. He did not seek a medical treatment because he experienced only slight pain. However, neck pain continued and cervical deformity gradually developed. Three months after the initial trauma, he visited an outpatient clinic because of his cervical deformity. Imaging examination demonstrated extreme kyphosis of the cervical spine. In addition to cervical deformity, spinal cord compression was observed in association with kyphosis on MRI, inducing cervical myelopathy. He underwent operative treatment including anterior decompression and fusion combined with posterior fusion with instrumentation.

Two years after surgery, he had no symptoms including neck pain and numbness of the upper or lower extremities. Short form-36 and Japanese orthopaedic association cervical myelopathy evaluation questionnaire scores showed remarkable improvement of quality of life at two-year follow up.

Conclusion: We reported rare case of severe cervical kyphosis after minor trauma. It is important to remember that severe kyphosis could be caused by minor trauma in adolescents.
\end{abstract}

\section{Introduction}

Cervical kyphotic deformity is rare in adolescents. We experienced the case of a 16-year-old male who developed severe cervical kyphosis after minor trauma without fracture or ligament injury. He showed cervical myelopathy due to cervical kyphosis. He underwent anterior and posterior surgery to treat his deformity and myelopathy.

*Corresponding author: Kazuyuki Watanabe, Department of Orthopaedic Surgery, Fukushima Medical University School of Medicine, Hikarigaoka, Fukushima 960-1295, Japan, Tel: +81 245471276; Fax: +81 245485505; E-mail: kazu-w@fmu.ac.jp

Citation: Watanabe K, Yabuki S, Otani K, Onda A, Nikaido T, et al. (2015) Severe Cervical Kyphosis in Adolescent after Minor Trauma - A Case Report. J Orthop Res Physiother 1: 018.

Received: August 24, 2015; Accepted: November 23, 2015; Published: December 07, 2015

\section{Case Report}

History

A sixteen-year-old male had experienced mild neck pain after falling in the bathroom 3 months previously. He did not seek a medical treatment because he experienced only slight pain. However, neck pain continued and cervical deformity gradually developed. Three months after the initial trauma, he visited an outpatient clinic because of his cervical deformity. It was very difficult for him to look upward because of his cervical deformity. Severe cervical spinal kyphosis was detected at the clinic on X-ray examination. He was referred to our hospital for surgery.

\section{Examination}

Cervical kyphosis was noted. The range of motion of the cervical spine was extremely limited. Neck pain was induced with cervical motion. The Jackson test and Spurling test were negative. Strength of grasp was $15 \times 15 \mathrm{~kg}$, and the result of the grip and release test [1] was $11 \times 11$ times. On neurological examination, upper extremity reflexes were normal, but the Patellar tendon reflexes and Achilles tendon reflexes were increased. Manual muscle testing revealed that the strength of the deltoid muscles and those of the upper extremities were decreased, indicating cervical myelopathy at C5 level. No other deformities were observed.

On X-ray examination, cervical kyphosis was observed. The angle of kyphosis from C3 to C5 was about $90^{\circ}$. The angle did not change with flexion or extension of the cervical spine (Figure 1). Magnetic Resonance Imaging (MRI) of the cervical spine revealed compression of the spinal cord between the $\mathrm{C} 3$ vertebral body to $\mathrm{C} 5$ vertebral body (Figures 2a-c). The intervertebral discs were not injured. No fracture was found on CT examination (Figure 2d).

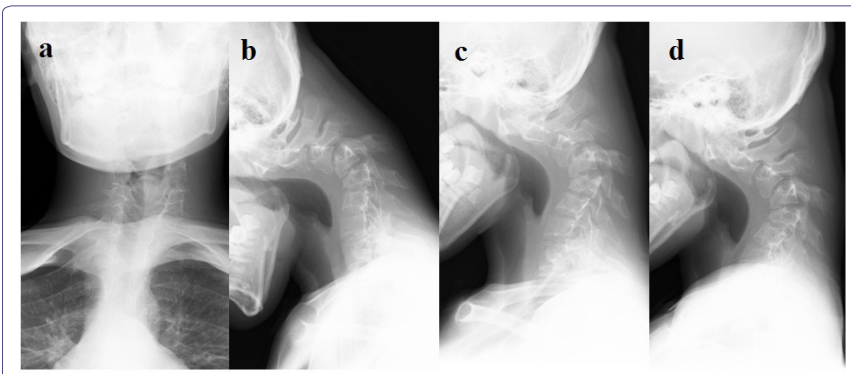

Figure 1: Images before surgery. X-ray findings on (a) Anteroposterior (b) Lateral views in neutral position; (c) Lateral view with flexion, and (d) Extension. Lateral X-ray showing severe kyphosis without flexibility. The angle of kyphosis was $90^{\circ}$

\section{Operation and postoperative course}

Before surgery, a recording electrode was placed at the Th11 level of the intradural space from the L $4 / 5$ interspinous process. Spinal cord monitoring was performed during surgery by recording motor cortex evoked potentials at the spinal cord after transcranial stimulation.

- The position was supine. A right anterior cervical incision was performed. The anterior aspect of the vertebral body was exposed and the $\mathrm{C} 3 / 4$ and $\mathrm{C} 4 / 5$ intervertebral discs were removed. This procedure enabled cervical spine correction. 

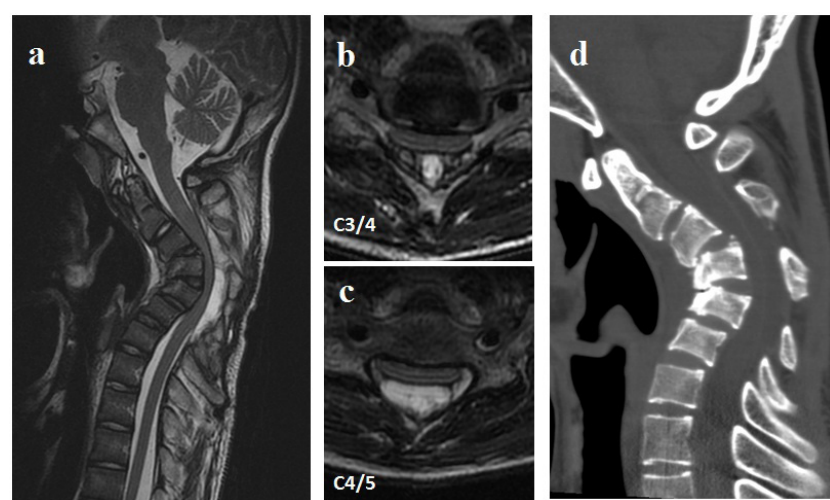

Figure 2: MRI and CT (a) MRI T2 weighted sagittal view; (b) MRI axial view at $\mathrm{C} 3 / 4$; (c) Axial view at C4/5 and (d) CT sagittal reconstruction. MRI showed kyphosis and cord compression from $\mathrm{C} 3$ to $\mathrm{C} 5$. CT revealed no fracture or dislocation of facet joints.

- The position was changed to prone. A midline incision of the cervical spine was performed with exposure from C3 to C7. The screws were inserted at the lateral mass of C3-6 (Medtronic ${ }^{\oplus}$ vertex system). The rod was bent to lordosis to achieve correction of kyphosis. After connecting the rod, moderate correction of cervical kyphosis was performed. The bone was harvested from the right posterior iliac crest and transplanted around the lateral mass of the cervical spine.

- The position was returned to supine. The anterior vertebral body was exposed again. Hemicorporectomy of C4 was performed. PLL was adherent to the dura mater. The caudal edge of the $\mathrm{C} 3$ vertebral body compressed the dural tube. Therefore, the caudal part of the C3 vertebral body was also removed. The dural tube was decompressed by this procedure. The bone graft was harvested from the right anterior iliac crest as a block and implanted between the $\mathrm{C} 3$ and $\mathrm{C} 5$ vertebral bodies.

Operative time was 7 hours and 3 minutes. Operative blood loss was $295 \mathrm{~g}$.

There were no findings of spinal monitoring indicating spinal cord dysfunction during surgery. The kyphosis was corrected from $90^{\circ}$ to $42^{\circ}$ on X-ray examination (Figure 3). Numbness of the hands was decreased immediately after operation. Walk disturbance was also improved. Ten days after operation, he was discharged from the hospital. By 3 months after operation, his symptoms had completely disappeared. Two years after operation, there was no difficulty in activities of daily life. Force of grasping had improved to over $30 \mathrm{~kg}$, and the grip and release tests were both 28 times. The $\mathrm{X}$-ray at 2 years after operation revealed union from C3 to C5. The angle of kyphosis was about $50^{\circ}$, and there was no progression of kyphotic deformity. Atlanto-dental interval was $7 \mathrm{~mm}$ (Figure 4a). The CT findings also showed bony union (Figure $4 \mathrm{~b}$ ).

The health-related Quality of Life (QOL) was evaluated using the Japanese version of the Short Form-36 (SF-36v2) [2] before and after operation. On SF-36, two summary scores, the Physical Component Score (PCS) and Mental Component Score (MCS), were evaluated in this study. SF-36 score was expressed as the deviation score, with 50 the national norm and over 50 better QOL than the national norm. In addition to the SF-36, the Japanese Orthopaedic Association Cervical Myelopathy Evaluation Questionnaire (JOACMEQ) [3,4] was also administered. The JOACMEQ includes 5 scales: cervical spine function, upper extremity function, lower extremity function, bladder function, and QOL. Before surgery, PCS was 36.7 and MCS was 49.8.

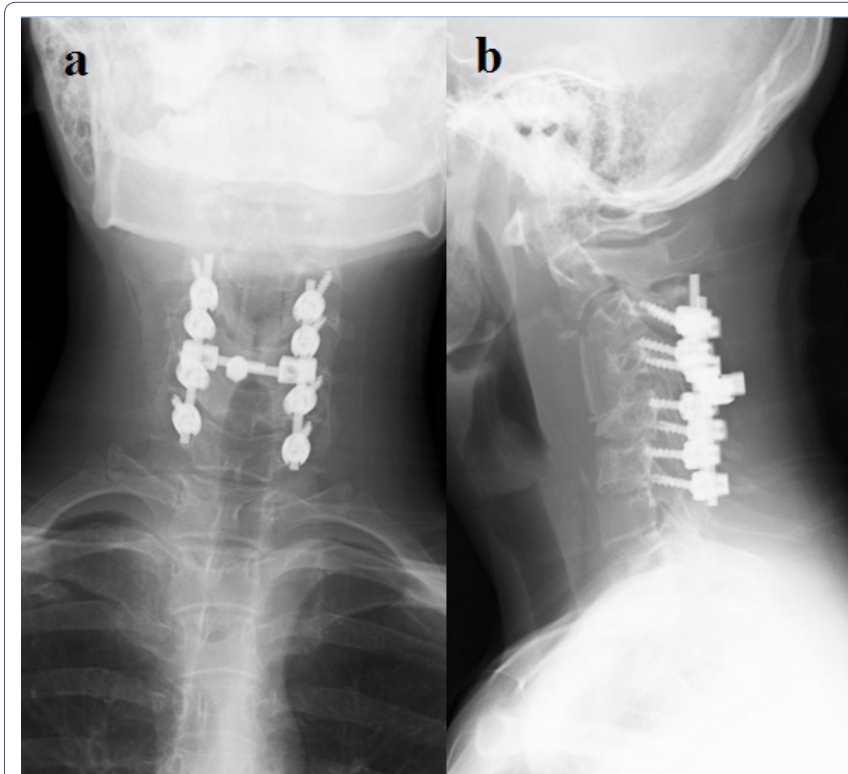

Figure 3: Images 1 week after surgery. (a) Anteroposterior, and (b) Lateral view. Posterior instrumentation was placed from $\mathrm{C} 3$ to $\mathrm{C} 6$ in addition to anterior fusion from C3 to C5. The angle of kyphosis was $42^{\circ}$.

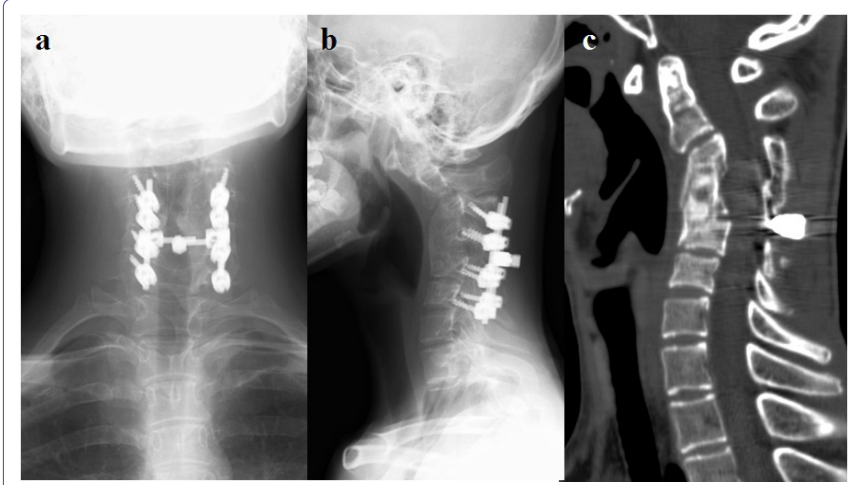

Figure 4: Images two years after surgery. X-ray findings on (a) Anteroposterior views; (b) Lateral view, and (c) CT sagittal reconstruction. Kyphosis was the same as just after surgery. There were no signs of instrumentation failure. CT showed anterior bony union.

These scores indicated that physical aspects of QOL before surgery were lower than the Japanese national average, while psychological QOL was almost the same as the national average. Two years after surgery, PCS was 53.3 and MCS was 49.9 (Table 1). These results indicated that physical QOL was improved after surgery and was higher than the Japanese national average. The JOACMEQ before surgery was low on each scale, especially the score for cervical spine function, which was 5/100 (Figure 5) (Table 2). Two years after surgery, the JOACMEQ was improved on all scales (Figure 5) (Table 2). These results indicated that both QOL and cervical spine function were improved after surgery.

\section{Discussion}

Many factors are related to kyphotic deformity of the cervical spine after trauma such as posterior ligaments injury, facet joint injury, vertebral disc injury, and vertebral fracture $[5,6]$. If the mid ligamentous column is injured, instability develops [7]. Injury of the posterior component of the cervical spine by hyperflexion is followed by localized kyphosis [8,9]. In this case, preoperative MRI did not disclose disruption of the posterior ligament. There were no findings 


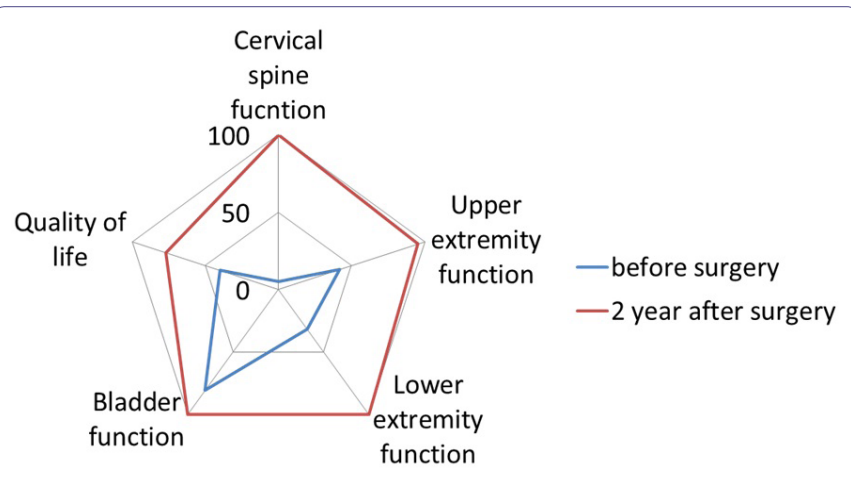

Figure 5: JOACMEQ Before and two years after surgery, the scores for cervical spine function were 5 and 100 , for upper extremity function 42 and 95, lower extremity function 32 and 100 , bladder function 81 and 100 , and QOL 40 and 77. These results indicated that all scales of the JOACMEQ were improved after surgery. In particular, cervical function, upper and lower extremity function, and bladder function were entirely satisfactory.

\begin{tabular}{|c|c|c|}
\hline & Before surgery & 2 years after surgery \\
\hline PCS & 36.7 & 53.3 \\
\hline MCS & 49.8 & 49.9 \\
\hline
\end{tabular}

Table 1: SF-36 before surgery, PCS was 36.7 , and lower than the Japanese national norm, while MCS was 49.8, the same as average. Two years after surgery, PCS was 53.3 and MCS was 49.9. These results showed that physical QOL 2 year after surgery was better than the Japanese national norm. Mental QOL was almost the same as average.

\begin{tabular}{|c|c|c|}
\hline & Before surgery & 2 years after surgery \\
\hline Cervical spine function & 5 & 100 \\
\hline Upper extremity function & 42 & 95 \\
\hline Lower extremity function & 32 & 100 \\
\hline Bladder function & 81 & 100 \\
\hline Quality of life & 40 & 77 \\
\hline
\end{tabular}

Table 2: JOACMEQ before and two years after surgery, the scores for cervical spine function were 5 and 100, for upper extremity function 42 and 95, lower extremity function 32 and 100, bladder function 81 and 100, and QOL 40 and 77. These results indicated that all scales of the JOACMEQ were improved after surgery. In particular, cervical function, upper and lower extremity function, and bladder function were entirely satisfactory.

of disc injury or fracture on MRI and CT. On operative examination, the nuchal ligament and posterior longitudinal ligament were not disrupted. There were no findings of tissue injury which could have caused kyphotic deformity. On the other hand, it was not clear whether he had congenital deformity or not, despite the fact that he and his family reported that he had no cervical deformity before injury. He also showed no findings indicating congenital syndromes such as Larsen syndrome and Marfan syndrome which often showed severe spinal deformities. There were no family histories of spinal deformity. Therefore, we considered his kyphosis was induced by minor trauma. We should remember that minor trauma such as just falling down in the bath room could induce severe cervical deformity [9].

Regarding the treatment of cervical kyphosis, surgery is indicated when the deformity is progressive or myelopathy accompanies it [10]. The goals of surgery are correction of kyphosis, decompression of the spinal cord, and stabilization of the cervical spine. Anterior alone [11-13], posterior alone [14], or combined anterior and posterior approaches [15-17] were reported as surgical strategies for cervical kyphosis. In this case, the kyphosis was considered rigid based on
$\mathrm{X}$-ray findings. We therefore planned three-staged surgery. His symptoms disappeared 3 months after surgery. His PCS of SF-36 and JOACMEQ scores markedly improved, indicating an excellent outcome. Preoperative MCS was almost the same as the national average. This finding indicated that psychological QOL did not decrease due to the disease. This might be the reason why psychological QOL did not improve after surgery. Bony union was observed on X-ray and CT examination without instrumentation failure. However, kyphosis persisted, at about $50^{\circ}$, indicating that decompression and stabilization could improve QOL in the cervical kyphosis patients with myelopathy even if the deformity remained. In addition to kyphosis, C1/2 instability was observed 1 year after surgery. These deformities did not progress on X-ray findings 2 years after surgery. However, anterior and posterior cervical fusion is a risk factor of second surgery for adjacent segment disease [18]. The risk of second surgery increase year by year [18]. Therefore, it is necessary to examine the X-ray regularly to check the progression of deformity even if he has no symptoms and has normal QOL.

\section{Conclusion}

We reported rare case of severe cervical kyphosis after minor trauma in adolescents. Three staged anterior-posterior-anterior procedure was adopted. It is important to remember that severe kyphosis could be caused by minor trauma in adolescents.

\section{References}

1. Ono K, Ebara S, Fuji T, Yonenobu K, Fujiwara K, et al. (1987) Myelopathy hand. New clinical signs of cervical cord damage. J Bone Joint Surg Br 69: 215-219.

2. Ware JE Jr (2000) SF-36 health survey update. Spine (Phila Pa 1976) 25: 3130-3139.

3. Fukui M, Chiba K, Kawakami M, Kikuchi S, Konno S (2009) JOA Back Pain Evaluation Questionnaire (JOABPEQ)/JOA Cervical Myelopathy Evaluation Questionnaire (JOACMEQ). The report on the development of revised versions. April 16, 2007. The subcommittee of the clinical outcome committee of the Japanese orthopaedic association on low back pain and cervical myelopathy evaluation. J Orthop Sci 14: 348-365.

4. Nikaido T, Kikuchi S, Yabuki S, Otani K, Konno S (2009) Surgical treatment assessment using the Japanese orthopedic association cervical myelopathy evaluation questionnaire in patients with cervical myelopathy: a new outcome measure for cervical myelopathy. Spine (Phila Pa 1976) 34: 2568-2572.

5. Allen BL Jr, Ferguson RL, Lehmann TR, O'Brien RP (1982) A mechanistic classification of closed, indirect fractures and dislocations of the lower cervical spine. Spine (Phila Pa 1976) 7: 1-27.

6. Schwarz N, Genelin F, Schwarz AF (1994) Post-traumatic cervical kyphosis in children cannot be prevented by non-operative methods. Injury 25: 173175.

7. McLain RF, Aretakis A, Moseley TA, Ser P, Benson DR (1994) Sub-axial cervical dissociation. Anatomic and biomechanical principles of stabilization. Spine (Phila Pa 1976) 19: 653-659.

8. Braakman M, Braakman R (1987) Hyperflexion sprain of the cervical spine. Follow-up of 45 cases. Acta Orthop Scand 58: 388-393.

9. Laporte C, Laville C, Lazennec JY, Rolland E, Ramare S, et al. (1999) Severe hyperflexion sprains of the lower cervical spine in adults. Clin Orthop Relat Res 126-134.

10. Iwasaki M, Yamamoto T, Miyauchi A, Amano K, Yonenobu K (2002) Cervical kyphosis: predictive factors for progression of kyphosis and myelopathy. Spine (Phila Pa 1976) 27: 1419-1425.

11. Herman JM, Sonntag VK (1994) Cervical corpectomy and plate fixation for postlaminectomy kyphosis. J Neurosurg 80: 963-970. 
12. Zdeblick TA, Bohlman HH (1989) Cervical kyphosis and myelopathy. Treatment by anterior corpectomy and strut-grafting. J Bone Joint Surg Am 71: 170-182.

13. Zdeblick TA, Hughes SS, Riew KD, Bohlman HH (1997) Failed anterior cervical discectomy and arthrodesis. Analysis and treatment of thirty-five patients. J Bone Joint Surg Am 79: 523-532.

14. Abumi K, Shono Y, Taneichi H, Ito M, Kaneda K (1999) Correction of cervical kyphosis using pedicle screw fixation systems. Spine (Phila Pa 1976) 24 2389-2396.

15. Mummaneni PV, Dhall SS, Rodts GE, Haid RW (2008) Circumferential fusion for cervical kyphotic deformity. J Neurosurg Spine 9: 515-521.
16. Nottmeier EW, Deen HG, Patel N, Birch B (2009) Cervical kyphotic deformity correction using 360-degree reconstruction. J Spinal Disord Tech 22: 385391.

17. O'Shaughnessy BA, Liu JC, Hsieh PC, Koski TR, Ganju A, et al. (2008) Surgical treatment of fixed cervical kyphosis with myelopathy. Spine (Phila Pa 1976) 33: $771-778$

18. Lee JC, Lee SH, Peters C, Riew KD (2014) Risk-factor analysis of adjacent-segment pathology requiring surgery following anterior, posterior, fusion, and nonfusion cervical spine operations: survivorship analysis of 1358 patients. J Bone Joint Surg Am 96: 1761-1767. 